\title{
Lipid-specific lgMs induce antiviral responses in the CNS: implications for progressive multifocal leukoencephalopathy in multiple sclerosis
}

Lorna Hayden', Tiia Semenoff', Verena Schultz', Simon F. Merz¹, Katie J. Chapple', Moses Rodriguez², Arthur E. Warrington ${ }^{2}$, Xiaohong Shi ${ }^{1}$, Clive S. McKimmie ${ }^{3}$, Julia M. Edgar ${ }^{1}$, Katja Thümmler ${ }^{1}$, Chris Linington ${ }^{1}$ and Marieke Pingen ${ }^{1 *}$ (D)

\begin{abstract}
Progressive multi-focal leukoencephalopathy (PML) is a potentially fatal encephalitis caused by JC polyomavirus (JCV). PML principally affects people with a compromised immune system, such as patients with multiple sclerosis (MS) receiving treatment with natalizumab. However, intrathecal synthesis of lipid-reactive IgM in MS patients is associated with a markedly lower incidence of natalizumab-associated PML compared to those without this antibody repertoire. Here we demonstrate that a subset of lipid-reactive human and murine IgMs induce a functional anti-viral response that inhibits replication of encephalitic Alpha and Orthobunyaviruses in multi-cellular central nervous system cultures. These lipid-specific IgMs trigger microglia to produce IFN- $\beta$ in a cGAS-STING-dependent manner, which induces an IFN- $\alpha / \beta$-receptor 1 -dependent antiviral response in glia and neurons. These data identify lipid-reactive IgM as a mediator of anti-viral activity in the nervous system and provide a rational explanation why intrathecal synthesis of lipid-reactive IgM correlates with a reduced incidence of iatrogenic PML in MS.
\end{abstract}

Keywords: Type-l interferon, Interferon stimulated genes, Viral encephalitis, John Cunningham polyomavirus (JCV), Microglia, IgM

\section{Introduction}

Neurotropic viral infections pose a major challenge when considering immune modulatory treatment for patients with autoimmune diseases. One of the most devastating of these consequences is progressive multi-focal leukoencephalopathy (PML), a rare demyelinating disease caused by opportunistic infection of the central nervous system (CNS) by JC polyomavirus (JCV; human polyomavirus 2) $[1,2]$. The seroprevalence of JCV in healthy adults is $40-$

\footnotetext{
* Correspondence: Marieke.Pingen@glasgow.ac.uk

${ }^{1}$ Institute of Infection, Immunity and Inflammation, University of Glasgow, Glasgow G12 8TA, UK

Full list of author information is available at the end of the article
}

$80 \%$, but the vast majority of infections are asymptomatic due to a robust immune response $[3,4]$.

However, immune-suppressed individuals are at an increased risk of developing PML [5]. This has important implications for the clinical management of primary and secondary immune deficiencies, as well as autoimmune diseases in which immunosuppression is a primary treatment option [4]. The latter include multiple sclerosis (MS), a chronic inflammatory demyelinating disease of the CNS [6], in which PML can develop in association with immunomodulatory disease modifying therapies including natalizumab [7] and fumaric acid esters [8].

Natalizumab is a humanised anti-alpha 4 integrinspecific antibody that significantly reduces disease activity

\section{BMC}

(c) The Author(s). 2020 Open Access This article is licensed under a Creative Commons Attribution 4.0 International License, which permits use, sharing, adaptation, distribution and reproduction in any medium or format, as long as you give appropriate credit to the original author(s) and the source, provide a link to the Creative Commons licence, and indicate if changes were made. The images or other third party material in this article are included in the article's Creative Commons licence, unless indicated otherwise in a credit line to the material. If material is not included in the article's Creative Commons licence and your intended use is not permitted by statutory regulation or exceeds the permitted use, you will need to obtain permission directly from the copyright holder. To view a copy of this licence, visit http://creativecommons.org/licenses/by/4.0/. The Creative Commons Public Domain Dedication waiver (http://creativecommons.org/publicdomain/zero/1.0/) applies to the data made available in this article, unless otherwise stated in a credit line to the data. 
by inhibiting migration of immune cells across the bloodbrain barrier (BBB) [9]. However, its use is limited by the risk of patients developing natalizumab-associated PML, which in JCV-seropositive patients exceeds 10 per 1000 after a 6 year treatment period $[7,10]$. There are no effective treatments for natalizumab-associated PML, other than plasma exchange to remove natalizumab from the circulation. However, as this itself may trigger immune reconstitution inflammatory syndrome (IRIS) mortality remains high and most survivors are left with severe neurological deficits [10].

Current efforts to counter the threat posed by natalizumab-associated PML focus on risk stratification [10]. This is based primarily on JCV serology, but a report identifying intrathecal synthesis of lipid-specific IgM antibodies as a factor associated with a lower probability of developing natalizumab-associated PML suggests an additional strategy [11]. Here, JCV seropositive patients lacking intrathecal IgM were 60 -fold more likely to develop PML than those positive for lipid-specific IgM. Importantly, patients positive for both JCV and intrathecal IgM had similar risk of developing PML as patients seronegative for JCV, suggesting these antibodies substantially contribute to JCV defences in the CNS [11]. Inspired by reports that disease-associated autoantibodies induce expression of type-I interferons (IFNs) in systemic lupus erythematosus [12], we speculated lipid-reactive IgM might act to enhance antiviral activity within the CNS.

We now demonstrate that a subset of human and murine IgM autoantibodies that recognise lipids in the CNS induce interferon- $\beta$ (IFN- $\beta$ ) in microglia. This response is STING-dependent and mediates IFN- $\alpha / \beta$-receptor 1 (IFNAR1)-dependent antiviral activity in all major CNS cell types (neurons, astrocytes, oligodendrocytes and microglia), as demonstrated by inhibition of replication of two unrelated encephalitogenic viruses (Bunyamwera virus (BUNV) and Semliki Forest virus (SVF)) in myelinating cell cultures. Our data provide a logical explanation for the observation intrathecal synthesis of lipid-specific IgM is associated with a reduced incidence of natalizumab-associated PML in MS.

\section{Materials and methods}

\section{Myelinated spinal cord cultures from rat}

Neurospheres were generated from the striata of postnatal day 1 Sprague-Dawley rats. Striata were mechanically dissociated in Leibovitz's L-15 Medium (Gibco) by glass Pasteur pipette and cultured in neurosphere media [Dulbecco's modified Eagle medium (DMEM)/F12 (Gibco), supplemented with $0.105 \% \mathrm{NaHCO}_{3}, 2 \mathrm{mM}$ glutamine, $1 \%$ penicillin-streptomycin (Pen/Strep), $5.0 \mathrm{mM}$ HEPES, $0.0001 \%$ bovine serum albumin (BSA), $25 \mu \mathrm{g} / \mathrm{ml}$ insulin, $100 \mu \mathrm{g} / \mathrm{ml}$ apotransferrin, $60 \mu \mathrm{M}$ putrescine, 20
$\mathrm{nM}$ progesterone, and $30 \mathrm{nM}$ sodium selenite (all from Sigma)]. Cultures were supplemented with $20 \mathrm{ng} / \mathrm{ml}$ recombinant murine epidermal growth factor (Peprotech) and maintained at $37^{\circ} \mathrm{C}$ in a humidified atmosphere of $7 \%$ $\mathrm{CO}_{2}$. Cells were fed every 3-4 days by addition of neurosphere medium and EGF. After 7 days, or when cells had formed large round neurospheres, the neurosphere suspension was centrifuged at $86 \mathrm{rcf}$ for 5 mins and resuspended in astrocyte media [DMEM $(1 \mathrm{~g} / \mathrm{ml}$ glucose, Gibco) supplemented with $10 \%$ foetal bovine serum (FBS) and $2 \mathrm{mM} \mathrm{L-glutamine} \mathrm{(both} \mathrm{Sigma)]} \mathrm{before} \mathrm{being} \mathrm{plated}$ onto poly-L-lysine $(13 \mu \mathrm{g} / \mathrm{ml})$ coated cover slips $(13-\mathrm{mm}$ diameter, VWR International). Every 3-4 days, half of the old media was replaced with fresh astrocyte media until cells formed a confluent monolayer.

Sprague-Dawley rats were time-mated. At embryonal development day (E)15.5, spinal cords were extracted from embryos, meninges removed and placed in $1 \mathrm{ml}$ Hank's Balanced Salt Solution (Sigma). Up to 6 cords/ml were then enzymatically digested with $2.5 \%$ trypsin $(100 \mu \mathrm{l} / \mathrm{ml})$ and $1.33 \%$ collagenase $(100 \mu \mathrm{l} / \mathrm{ml})$ (both Sigma) for 15 mins at $37^{\circ} \mathrm{C}$. Enzymatic activity was stopped by adding $2 \mathrm{ml}$ of SD inhibitor [L-15 media supplemented with $0.52 \mathrm{mg} / \mathrm{ml}$ soybean trypsin inhibitor, $3.0 \mathrm{mg} / \mathrm{ml} \mathrm{BSA}$, and $0.04 \mathrm{mg} / \mathrm{ml}$ DNase (all Sigma)] per $1 \mathrm{ml}$ HBSS. The cords were then triturated, centrifuged at $196 \mathrm{rcf}$ for $5 \mathrm{mins}$, resuspended in plating medium [50\% DMEM, 25\% horse serum, 25\% Hank's Balanced Salt Solution (HBSS)] and plated onto the aforementioned neurosphere-derived astrocytes at a density of 150,000 cells per coverslip. Coverslips were contained in $35 \mathrm{~mm}$ Petri dishes, three $13 \mathrm{~mm}$ coverslips per dish, and placed in an incubator for $2 \mathrm{~h}$. Cells were topped up with $450 \mu \mathrm{l}$ of plating medium and $600 \mu \mathrm{l}$ of differentiation medium [DMEM $(4.5 \mathrm{~g} / \mathrm{ml}$ glucose $), 10 \mathrm{ng} / \mathrm{ml}$ biotin, $0.5 \% \mathrm{~N} 1$ supplement, $50 \mathrm{nM}$ hydrocortisone, and $0.1 \mu \mathrm{g} / \mathrm{ml}$ insulin (all from Sigma)]. Cells were fed every $2-3$ days by removing $500 \mu \mathrm{l}$ of old media and replacing with $600 \mu \mathrm{l}$ of fresh differentiation media. From DIV13, cells were fed with differentiation media without added insulin $\left(\mathrm{DM}^{-}\right)$.

\section{Myelinated spinal cord cultures from mouse}

Myelinating spinal cord cultures were generated from embryos of a number of mouse strains including; C57/ B16 mice (Jackson Laboratories), Ifnar ${ }^{+/+}$and Ifnar ${ }^{-/-}$ mice on a 129S7/SvEvBrdBklHprtb-m2 background (B\&K Universal) and $\mathrm{Cst}^{+/+}, \mathrm{Cst}^{+/-}$and $\mathrm{Cst}^{-1-}$ mice on a C57/Bl6 background (Prof. Hugh Willison). Mice were time-mated and pregnant females were killed by $\mathrm{CO}_{2}$ overdose at E13.5. Spinal cords were extracted from embryos and processed as per rat myelinating culture protocol with some amendments. Cords were enzymatically digested with $2.5 \%$ trypsin $(100 \mu \mathrm{l} / \mathrm{ml})$ for $15 \mathrm{mins}$ 
at $37^{\circ} \mathrm{C}$. Enzymatic activity was stopped by adding $2 \mathrm{ml}$ SD inhibitor. Cords were triturated, centrifuged at $181 \mathrm{rcf}$ and resuspended in plating medium. Cells were plated onto $13 \mathrm{~mm}$ diameter glass coverslips coated with poly-L-lysine $(0.1 \mathrm{mg} / \mathrm{ml}$ in boric acid buffer, $\mathrm{pH} 8.4)$ at a density of 165,000 cells per coverslip. Coverslips were contained in $35 \mathrm{~mm}$ Petri dishes, 3 coverslips per dish, and incubated for a minimum of $4 \mathrm{~h}$ to attach. Once visibly attached, dishes were topped up with $300 \mu$ plating media and $600 \mu \mathrm{l}$ differentiation media. Cells were fed as per the rat culture protocol.

\section{Antibody production}

Once proliferating at a stable rate, cells were transferred to a CELLine cell culture flask (BD Biosciences). Cells were seeded in ultra-low endotoxin media [OptiMem supplemented with $10 \%$ ultra-low endotoxin FBS (VWR) and $1 \%$ Pen/Strep] at a density of $1.5 \times 10^{6}$ cells $/ \mathrm{ml}$ and maintained at a density of maximum $1.5 \times 10^{6}$ cells $/ \mathrm{ml}$, supernatants collected and stored at $-20^{\circ} \mathrm{C}$ until antibody purification. $\mathrm{O} 4$ and $\mathrm{A} 4 \mathrm{CD}$ antibodies were purified under sterile conditions from supernatants using Hi-Trap IgM purification HP columns (GE Healthcare) as per manufacturer's instructions. All buffers were made using sterile ultra-low endotoxin reagents. Eluted protein was dialysed in a Spectra/Por 6 Regenerated Cellulose Dialysis Membrane (Spectrum Labs) against endotoxin tested Dulbecco's phosphate buffered saline (Invitrogen) for $24 \mathrm{~h}$ at $4{ }^{\circ} \mathrm{C}$. Final antibody concentration was determined by Nanodrop (Denovix DS-11) and solution diluted to $1 \mathrm{mg} / \mathrm{ml}$ in DPBS.

\section{Antibody treatment}

Cultures were treated at day in vitro 24 (DIV24). To treat cultures, $500 \mu \mathrm{l}$ of media was removed and $500 \mu \mathrm{l}$ of treatment added. Treatments were diluted in differentiation media. All antibodies were used at a final concentration of $20 \mu \mathrm{g} / \mathrm{ml}$. Antibodies used in treatments included; IgM from mouse myeloma (Sigma), A4CD, O4, O1 (R\&D Systems or in-house produced), A2B5 (Abcam), rhIgM22, shIgM22, rhIgM12, shIgM12, shIgM42 and shIgM201 (kindly provided by MR and AW). Untreated controls were given differentiation media alone. For IFN- $\beta$ neutralisation, DIV24 rat cultures were treated with media alone, $\mathrm{A} 4 \mathrm{CD}$ or $\mathrm{O} 4$ in combination with either rabbit anti-rat IFN- $\beta$ neutralising antibody or normal rabbit IgG control $(10 \mu \mathrm{g} / \mathrm{ml}, \mathrm{R} \& D$ Systems) for $24 \mathrm{~h}$.

\section{Virus infections}

BUNVGc-eGFP is a recombinant BUNV, in which the N-terminal 326 amino acid of the viral membrane Gc glycoprotein was replaced by eGFP [13]. In short, BSRT7/5 cells were transfected with $1 \mu \mathrm{g}$ pT7riboBUNL(+), pT7riboBUNS(+), and pT7riboBUNMGc-eGFP. After 5 h, growth media [Glasgow Minimum Essential Medium supplemented with $10 \%$ tryptose phosphate broth, $10 \%$ FBS, and (Gibco) and $1 \mathrm{mg} / \mathrm{ml}$ Geneticin (G418) sulfate (Calbiochem)]. Cells were incubated for 5-11 days at $33^{\circ} \mathrm{C}$ until cytopathic effect was observed. Supernatant was clarified and stored at $-70^{\circ} \mathrm{C}$ until use.

For all eGFP-Semliki Forest Virus (SFV) experiments we used an eGFP expressing variant of the neurovirulent strain SFV4. The eGFP marker gene was inserted in nsP3 via a naturally occurring XhoI site, resulting in plasmid pCMV-SFV4(Xho-EGFP)4 which was generated and kindly provided by prof Andres Merits (University of Tartu). The backbone of this plasmid has been previously described [14], further details are available from the Lead Author. Virus stocks were generated by electroporating this plasmid in BHK cells and propagated in Glasgow Minimum Essential Medium (Gibco) with 5\% FBS, 10\% tryptose phosphate broth (Gibco), 1\% Pen/ Strep at $37^{\circ} \mathrm{C}$ in $5 \% \mathrm{CO}_{2}$. When severe cytopathic effect was observed, virus-containing supernatant was centrifuged $500 \times \mathrm{g}$ for $30 \mathrm{~min}$ to remove cellular debris and cell-free virus stored in small aliquots at $-70^{\circ} \mathrm{C}$. Stocks were titrated by plaque assay as described below.

DIV24 cultures were treated with either media alone, $\mathrm{A} 4 \mathrm{CD}$ or $\mathrm{O} 4$ for $24 \mathrm{~h}$. All media was removed and cells inoculated with $0.75 \%$ BSA (Sigma) in PBS alone or with BUNV (MOI 1 ) for $1 \mathrm{~h}$ at $5 \% \mathrm{CO}_{2}$, shaking gently every $15 \mathrm{~min}$ or SFV (MOI 1 ) for $1 \mathrm{~h}$ at room temperature on a plate shaker. Inoculum was removed and fresh differentiation media was added. Cells were then incubated for a further $6-24 \mathrm{~h}$, at which point supernatant was collected for plaque assay, cells washed with $0.75 \%$ BSAPBS and prepared for further analysis.

To quantify virus stocks and production of BUNV, Vero E6 cell monolayers were incubated with serially diluted supernatant for $1 \mathrm{~h}$ at $37^{\circ} \mathrm{C}$ then covered with $0.6 \%$ Avicel (FMC Biopolymer)-minimum essential medium overlay medium supplemented with $2 \%$ FBS. Cells were incubated for 4 days and fixed with $4 \%$ formaldehyde-PBS and stained with $0.5 \%(\mathrm{w} / \mathrm{v})$ methyl violet. Virus titres were calculated and presented as $\mathrm{PFU} / \mathrm{ml}$. A similar assay was used for SFV, with the following adaptations: BHK cells were infected and maintained as described, and at 2 days post infection fixed in $10 \%$ formaldehyde-PBS and stained with $0.1 \%$ toluidine blue (Sigma).

\section{Drug treatment of cultures}

To deplete microglia, rat cultures were treated from DIV18-28 with PLX3397 (Selleckchem) or an equivalent volume of dimethyl sulfoxide (DMSO, Sigma) every 2-3 days. Final concentration of PLX3397 in cell culture dish was maintained at $1 \mu \mathrm{M}$ and volume of DMSO maintained at $0.1 \%$ of total media volume. For signalling 
pathway inhibition, DIV24 rat cultures were treated $6 \mathrm{~h}$ with media alone, A4CD or $\mathrm{O} 4$ with simultaneous administration of either DMSO or $10 \mu \mathrm{M}$ of one of the following inhibitors; ST2825 (MedChemExpress), RU.521 (Invivogen), C-176 (Biovision) and BX795 (Invivogen).

\section{Fluorescence in situ hybridisation (FISH)}

FISH was performed on DIV24 rat myelinating cultures treated $24 \mathrm{~h}$ with either A4CD or O4 using the ViewRNA Cell Plus Assay kit (Invitrogen) as per manufacturer's instructions. First, immunocytochemistry was performed against the following antigens; GFAP (1:200, Sigma), NeuN (1:400, Millipore), Olig2 (1:500, Millipore) and Iba1 (1:500, Wako), using secondary antibodies AlexaFluor488 goat anti-rabbit IgG and AlexaFluor568 goat anti-mouse IgG1 (both Invitrogen). ViewRNA cell plus type 6 probe sets against the following genes were used; Cxcl10, Mx1, Rsad2 and Oasl. Coverslips were mounted onto glass slides using Mowiol 4-88 mounting medium. Mounted slides were stored overnight at $4{ }^{\circ} \mathrm{C}$ protected from light and imaged.

\section{RNA isolation}

RNA was extracted from rat cultures using the RNeasy Plus Micro kit (Qiagen) as per manufacturer's instructions. RNA was extracted from mouse and virally infected cultures by removing all media from cells, adding $1 \mathrm{ml} \mathrm{TRIzol}{ }^{\circ}$ Reagent per dish and incubating for 10 min. Lysates were transferred to RNase-free tubes (Invitrogen) and stored at $-80^{\circ} \mathrm{C}$ until use. RNA was isolated using the PureLink ${ }^{\mathrm{m}}$ RNA Mini Kit (Invitrogen) as per manufacturer's instructions. Concentration and quality of RNA was determined by Nanodrop.

\section{Microarray}

RNA from treated DIV24 rat myelinating cultures (mock, $20 \mu \mathrm{g} / \mathrm{ml} \mathrm{O} 4$ or IgM isotype control for $24 \mathrm{~h}$ ) was quality checked with the Agilent Bioanalyzer 6000 Nano LabChip platform and biotin labelled using Ambion WT Expression Kit. The labelled RNA was then hybridized to Affymetrix GeneChip Rat Gene 2.1 ST Arrays according to manufaturer's instructions using the Fluidics Station 450 and scanned on Gene Array Scanner 3000-7G. Each treatment group (untreated Control, O4 and IgM treatment) were set up in three replicates, analysed in Partek Genomics Suite (version 6.6, Partek) and deposited in Gene Expression Omnibus database (https://www.ncbi.nlm.nih. gov/geo/) under accession number GSE150331. Probe set level data were normalized using GC-RMA method and One-Step Tukey's Biweight method was used to summarize to transcript cluster level. Differential expression was then calculated by one-way ANOVA comparing O4-treatment vs Control, O4-treatment vs IgM-treatment and IgM-treatment vs Control. Differentially expressed genes (fold-change $> \pm 1.4$, FDR-adjusted $p$-value $<0.05$ ) were then analysed for enriched KEGG pathways using Partek Pathway and for the presence of interferon regulated genes (IRGs) using the interferome database (v2.01; http://www.interferome.org/interferome/home.jspx) [15].

\section{CDNA synthesis and quantitative real-time PCR}

Primer 3 software (http://biotools.umassmed.edu/bioapps/ primer3_www.cgi) [16] was used to find suitable primer sequences on mRNA sequences from the NCBI nucleotide data base, and checked for specificity using BLAST (http://blast.ncbi.nlm.nih.gov/Blast.cgi). cDNA was synthesized from a maximum of $1 \mu \mathrm{g}$ RNA using a QuantiTect $^{\circ}$ Reverse Transcription Kit (Qiagen) following the manufacturer's instructions using a Biometra T3 Thermocycler (Thermofisher). Synthesised cDNA was diluted to appropriate volume using RNase-free water (1:200 for $1 \mu \mathrm{g}$ starting RNA). Quantitative real-time PCR was performed in MicroAmp Fast Optical 96-well reaction plates $(0.1 \mathrm{ml})$ (Invitrogen) with each sample being run in triplicate. Reagents per well were as follows; $7.5 \mu \mathrm{l}$ Power SYBR $^{\text {ti }}$ Green PCR Master Mix (Applied Biosystems), 5.2ul RNase-free water, 0.3ul primer mix (Integrated DNA Technologies, $50 \mu \mathrm{M}$ /primer) and $2 \mu \mathrm{l}$ cDNA. Plates were run in an Applied Biosystems Fast Real-Time PCR System (ABI 7500) and quantified using the comparative CT $(\triangle \triangle \mathrm{CT})$ method or, for human IgM data alone, standard curve method. Cycle settings were as follows; $50^{\circ} \mathrm{C}$ for 5 min, $95^{\circ} \mathrm{C}$ for $10 \mathrm{~min}$, followed by 40 cycles of $95^{\circ} \mathrm{C}$ for $15 \mathrm{~s}, 60^{\circ} \mathrm{C}$ for $1 \mathrm{~min}$, and a final dissociation step at $95^{\circ} \mathrm{C}$ for $15 \mathrm{~s} .18 \mathrm{~S}$ was used as the housekeeping gene for mouse experiments and virus experiments. Gapdh was used as the housekeeping gene for all other rat experiments.

\section{Immunocytochemistry}

Cultures were fixed with $4 \%$ formaldehyde- $2 \%$ sucrose in PBS for $10 \mathrm{~min}$. Fixative was replaced by $0.75 \%$ BSAPBS, and cultures stored at $4{ }^{\circ} \mathrm{C}$ until immunocytochemistry was performed. Fixed cells were permeabilised with $0.5 \%$ Triton $\mathrm{X}$ for $10 \mathrm{~min}$, washed with PBS, blocked with blocking buffer [1\% BSA, 10\% horse serum in PBS] for $45 \mathrm{~min}$, incubated with primary antibody diluted in blocking buffer for $45 \mathrm{~min}$, washed with PBS and incubated in dark with secondary antibody diluted in blocking buffer for $15 \mathrm{~min}$. Coverslips were then washed in PBS followed by $\mathrm{dH}_{2} \mathrm{O}$ and mounted onto glass slides with Mowiol 4-88 mounting medium [33\% w/v Mowiol ${ }^{\circ}$ 4-88, 13.2\% w/v glycerol (both Sigma), 0.05\% v/v DAPI (Invitrogen) in $0.13 \mathrm{M}$ Tris $\mathrm{pH}$ 8.5]. Primary antibodies against the following proteins were used; BUN virions (1:500, Elliott lab), NeuN (1:400, Millipore), Nestin (1: 200, Millipore), GFAP (1:200, Sigma), Olig2 (Millipore, 1:200), ED1 (1:100, Abcam), Iba1 (1:500, Wako), A4CD, O4 (both $20 \mu \mathrm{g} / \mathrm{ml}$, both Linington Lab), O1 $(20 \mu \mathrm{g} / \mathrm{ml}$, 
R\&D Systems) and A2B5 (20 $\mu \mathrm{g} / \mathrm{ml}$, Abcam). All secondary antibodies were purchased from Invitrogen and used at 1:400 including; AlexaFluor488 goat anti-rabbit IgG, AlexaFluor488 goat anti-mouse IgM, AlexaFluor568 goat anti-mouse IgG1 and AlexaFluor568 goat anti-mouse IgG2a. For live-staining of lipid-specific IgM, live cells were incubated with antibody $\left(20 \mu \mathrm{g} / \mathrm{ml}, 30 \mathrm{~min}, 4{ }^{\circ} \mathrm{C}\right)$ and then fixed with $4 \%$ PFA. Protocol continues as above.

\section{Image capture and analysis}

All imaging and quantification was performed blind. Coverslips from microglia depletion experiments and BUNV infections were imaged on an Olympus BX51 microscope (Olympus Lifescience) using a Retiga R6 camera and Ocular 2.0 software (both Teledyne Qiamging). Ten images were taken per coverslip, 3 coverslips per condition for every biological replicate. Images were saved as 16 bit tif files and converted to 8 bit png files using CellProfiler [17] pipeline "Ocular.cpproj". Total dapi for each png image was quantified using CellProfiler pipeline "dapi mono.cp". Both pipelines can be found at https://github.com/muecs/ $\mathrm{cp} /$ tree/v1.1. Iba1-positive cells and BUNV-positive cells were counted manually using cell counter plugin (https:// imagej.nih.gov/ij/plugins/cell-counter.html) with ImageJ [18]. Co-localisation of BUNV-positive dapi with other cell markers was also quantified using the cell counter plugin.

Coverslips from FISH experiments were imaged using a Zeiss Axio Imager 2 and Zen 2012 (blue edition) software. To quantify total dapi, images were saved as png files using Zen software and processed using the "dapi mono.cp" CellProfiler pipeline. Cells positive for mRNA of interest were quantified manually using the cell counter plugin in Fiji [19]. Co-localisation of mRNA-positive dapi with other cell markers was also quantified using the cell counter plugin.

\section{Statistical analysis}

Statistical details of experiments including statistical tests used, $\mathrm{n}$ values and what $\mathrm{n}$ represents, definition of centre, dispersion and precision measures are reported in the figure legends. Statistical significance was determined using one of the following tests depending on number of samples and variables; two-tailed t-test for data with one variable and two conditions, one-way ANOVA with Tukey's post hoc test for data with one variable and greater than two conditions, and two-way ANOVA with Bonferroni post hoc test for data with two variables and two conditions. Data were deemed significant when $p$-value was less than 0.05 and are denoted in figures as $" p<0.05, * * p<0.01,{ }^{* * * *} p<0.001$. Statistical analysis was performed in GraphPad Prism 8.

\section{Data availability}

The microarray data generated for this study are available at the GEO repository under the following accession number GSE150331 and as supplemental information. CellProfiler pipelines can be found at https:/github.com/muecs/ $\mathrm{cp} /$ tree/v1.1

All other data supporting the findings of this study are available in the article, the Supplementary information files, or upon request to the authors. We are happy to provide a source table.

\section{Results}

Lipid-specific IgM provides protection against neurotropic viruses in an IFNAR1 -dependent manner

To test the hypothesis that lipid-specific IgMs induce a functional anti-viral response in the CNS, we examined the anti-viral properties of the murine IgM monoclonal antibody (mAb) O4, recognising sulfatide (3-O-sulfogalactosylceramide), a major target of the intrathecal antibody response in MS [20]. The antiviral properties of this antibody were tested in rodent myelinated cultures, which replicate much of the cellular and functional complexity of the nervous system in vivo in a tractable in vitro model [21].

To mimic the situation in MS patients who have intrathecal lipid-specific IgM in their CNS before JCV disseminates to the CNS, rat myelinated cultures were pretreated for $24 \mathrm{~h}$ with $\mathrm{O} 4$ or isotype control A4CD, an IgM mAb specific to myelin oligodendrocyte glycoprotein (MOG) peptide. Both were purified in our laboratory under the same conditions. As JCV is an obligatory human pathogen, we used BUNV as an encephalitic model virus to infect the pre-treated cultures. BUNV, a prototype for both the orthobunyavirus genus and Peribunyaviridae family, is a tripartite negative sense singlestranded enveloped RNA virus [22] and can induce severe encephalitis in domestic animals [23].

As the cellular tropism of BUNV in rodents is unknown this was first mapped by immune fluorescence microscopy using a GFP-tagged BUNV (BUNVGc-eGFP) [13] and a panel of cell type specific markers to reveal that BUNV preferentially infected cells of the neuronal lineage in myelinating cultures (Fig. 1a, b \& i). Pretreatment with $\mathrm{O} 4$ had a profound antiviral effect as demonstrated by quantifying BUNVGc-eGFP infected cells by immune fluorescence microscopy $(p<0.05)$ (Fig. $1 c, d \& j$ ). This finding was corroborated when assessing BUNV RNA expression by RT-PCR, where a $>10$-fold decrease was observed in BUNM transcript in O4treated cultures ( $p=0.1303$ ) (Fig. 1k).

Considering our myelinated cultures lack adaptive immune cells, we hypothesised that this antiviral effect might be conferred by the innate antiviral type-I IFN pathway. To investigate this hypothesis, experiments 

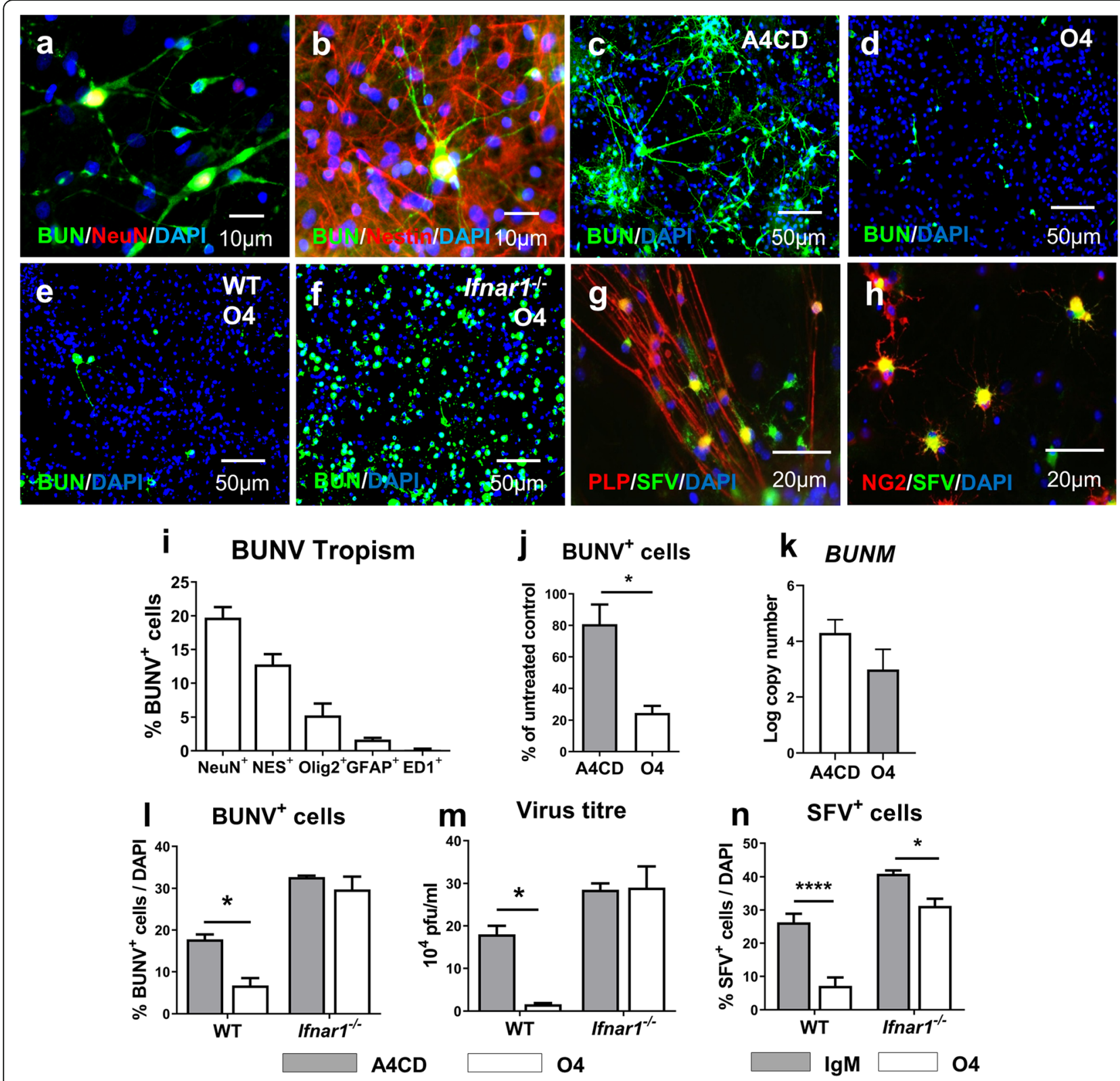

Fig. 1 Lipid-specific IgM provides protection against neurotropic viruses in an IFNAR1-dependent manner. a-d, i-k Rat cultures pre-treated $24 \mathrm{~h}$ with $\mathrm{A} 4 \mathrm{CD}$ or $\mathrm{O} 4$ and infected with BUNV $(\mathrm{MOI}=1)$. $\mathbf{a}, \mathbf{b}$ BUNV-infected mature neurons and neuronal progenitor. $\mathbf{c}, \mathbf{d}$ A4CD and O4-treated cultures infected with BUNV. i BUNV tropism. j, k Immunocytochemical and RT-qPCR analysis. Data presented as mean \pm SEM and analysed by paired twotailed t-test. $\mathbf{j} n=4 \mathbf{k} n=3$. e, $\mathbf{f}, \mathbf{I}, \mathbf{m}$ WT and Ifnar ${ }^{-1-}$ mouse cultures treated and infected as above. e, $\mathbf{f}$ BUNV-infected WT and Ifnar $1^{-/-}$cultures pretreated with $\mathrm{O} 4$. I, $\mathbf{m}$ Immunocytochemical and plaque assay analysis. Data presented as mean \pm SEM, analysed by two-way ANOVA and significant difference determined by Sidak's post-hoc test. I WT $n=2$, Ifnar ${ }^{-1-} n=3 \mathbf{m} n=2$ for all conditions. $\mathbf{g}, \mathbf{h}, \mathbf{n}$ WT and Ifnar ${ }^{-1-}$ mouse cultures treated as above and infected with SFV. $\mathbf{g}$, h SFV-infected mature oligodendrocytes and oligodendrocyte progenitors. $\mathbf{n}$ Immunocytochemical analysis. Data presented as mean \pm SEM, analysed by two-way ANOVA and significant difference determined by Sidak's post-hoc test. $n=4$ for all conditions. Significant differences denoted as ${ }^{*} p<0.05$ and ${ }^{* * *} p<0.0001$

were repeated in myelinated cultures derived from Ifnar $1^{-/}$mice and wild type controls, resulting in a significant decrease in BUNVGc-eGFP infected cells and supernatant viral titre in O4-treated wild type (WT) cultures only, highlighting the dependency of this response on the type-I IFN pathway (Fig. 1e, f, l \& m). Moreover, this also demonstrates the protective effect of $\mathrm{O} 4$ is not species-specific as it induced a similar level of antiviral activity to that observed in rat cultures.

To investigate whether this protection can be extended to other viruses with a different cellular tropism and generating different Pattern Associated Molecular Patterns 
(PAMPs), we investigated the antiviral potential of $\mathrm{O} 4$ using SFV. SFV is an encephalitogenic positive-sense single-stranded RNA virus that preferentially infects cells of the oligodendroglial lineage [24] (Fig. 1g \& h) (construct kindly provided by Andres Merits). As observed for BUNV, pre-treatment with $\mathrm{O} 4$ inhibited replication of SFV in WT cultures $(p<0.001)$, but in this case a residual protective effect was observed in Ifnar $1^{-/-}$cultures $(p<$ 0.05) (Fig. 1n). This may be due to steric hindrance of antibody that is bound to the oligodendrocyte cell surface restricting viral access and/or disruption of receptormediated endocytosis but nonetheless, the dominant protective effect is largely IFNAR1-dependent.

Together these results demonstrate that the lipidspecific IgM mAb O4 exhibits antiviral properties that can inhibit virus replication in neurons and glia in an IFNAR1-dependent manner. This supports the idea that intrathecal lipid-specific IgM found in MS patients may contribute to protection against JCV and limit risk of PML.
Lipid-specific lgM induces an antiviral transcriptional signature in vitro

To gain further insight into the mechanistic basis of this antiviral response, a microarray was performed on cultures treated for $24 \mathrm{~h}$ with O4, IgM isotype control or media alone. O4 differentially regulated 543 transcripts compared to the IgM control (431 upregulated, 112 down regulated; fold-change $\geq \pm 1.4$; FDR-adjusted $p \leq 0.05$ ), whilst no significant differences were observed between untreated and IgM control-treated cultures (Fig. 2a, GSE150331).

The transcriptional response induced by $\mathrm{mAb} \mathrm{O} 4$ was characterised by increased expression of multiple genes that play important roles in the development of antiviral responses in the CNS (Fig. 2b and Table S1). These include chemokines (chemotactic cytokines) Cxcl10 and $\mathrm{Ccl5}$, the products of which co-ordinate recruitment of immune effector cells into the CNS, [25], as well as numerous genes such as Oasl, Mxl and Rsad2, which encode proteins that restrict viral replication [26]. It is

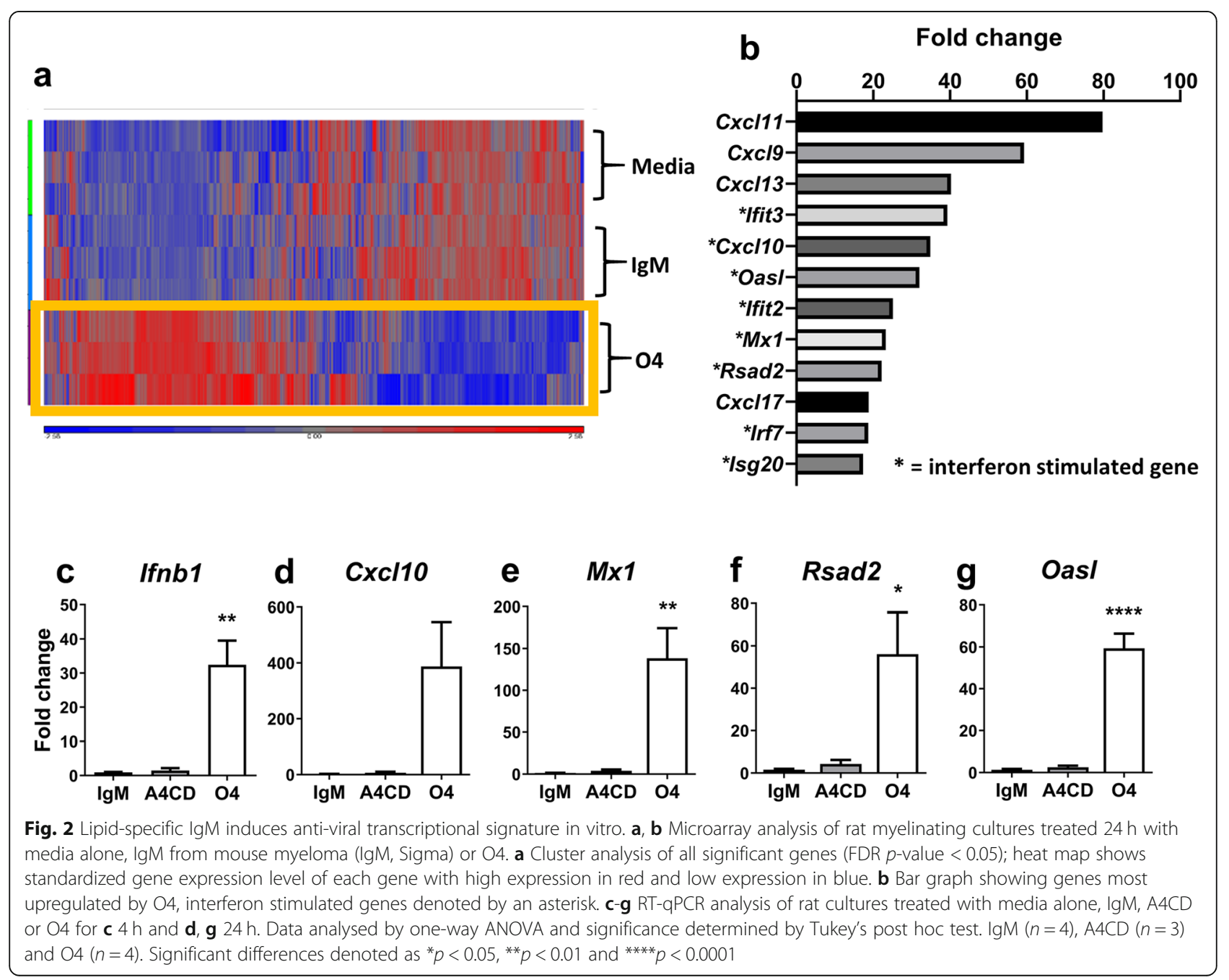


therefore not surprising that pathway enrichment analysis identified viral diseases as the most significantly enriched human disease pathways associated with this response (Table S2). Moreover, the other most significantly enriched organismal system pathways included NOD-like, Toll-like and RIG1-like signaling pathways (Table S3). These observations led us to speculate the IFN-like response triggered by $\mathrm{O} 4$ involves activation of one or more Pattern Recognition Receptor (PRR)dependent pathways; a concept supported by the demonstration that as much as $72 \%$ of all differentially regulated genes are interferon-stimulated genes (ISGs) based on the murine interferome database (Fig. $2 \mathrm{~b}$ and Table S1) [15].

To validate these microarray data, we selected IFN $-\beta$ and several top-ranking ISGs for RT-qPCR analysis. Ifnbl was rapidly and significantly upregulated within 4 h of O4 treatment $(p<0.01)$ (Fig. 2c). After 24 h, we observed a significant upregulation of the chemokine genes Cxcl10 ( $p=0.0552)$ and Ccl5 $(p<0.05)$, and the antiviral transcripts Oasl $(p<0.0001), M x 1(p<0.01), \operatorname{Rsad} 2(p<$ $0.05)$, Ifit2 $(p<0.01)$, Isg15 $(p<0.01)$, and Isg20 $(p<0.05)$ (Fig. 2d-g and Suppl. Fig. 1A-D) compared to the IgM and untreated controls.

In summary, these data demonstrate that $\mathrm{O} 4$ induces an "IFN-like" response in CNS cells, explaining the potent antiviral effect of $\mathrm{O} 4$ against two genetically distinct neurotropic model viruses.

\section{The response induced by 04 is IFN- $\beta$ - and IFNAR- dependent}

To investigate the importance of IFN signalling for this response, we first mapped the kinetics of IFN and ISG expression induced by O4. Expression of Ifnb1 was detected after $4 \mathrm{~h}$, peaked at $8 \mathrm{~h}$ and then declined slowly over the following $10 \mathrm{~h}$ (Suppl. Fig. 2A). In contrast, ISG expression increased markedly between 8 and $18 \mathrm{~h}$ posttreatment (Suppl. Fig. 2B-H). Induction of Ifnb1 and these selected ISGs was not observed in cultures treated with control IgM (Fig. 2c-g).

To assess whether the O4 response was dependent on type-I IFN signalling, WT and Ifnar $1^{-/-}$mouse myelinating cultures were treated with media alone, control IgM (A4CD) or O4 for $24 \mathrm{~h}$. Induction of ISGs by O4 was abrogated almost completely in Ifnar $1^{-/-}$cultures, showing a significant interaction between the presence of Type I IFN receptors and upregulation of Cxcl10 ( $p<$ $0.0001), M x 1(p<0.01)$, Rsad2 $(p<0.001)$ and Oasl $(p<$ 0.001 ) (Fig. 3a-d). Induction of ISGs by O4 is therefore mediated predominantly via activation of the type-I IFN pathway.

To confirm the ISG induction was specifically IFN- $\beta$ dependent as indicated by the mRNA expression data (Suppl. Fig. 2A), rat myelinating cultures were treated for $24 \mathrm{~h}$ with $\mathrm{A} 4 \mathrm{CD}$ or $\mathrm{O} 4$ in the presence of an IFN- $\beta$ neutralising antibody or rabbit IgG as a control. O4induced ISG expression was attenuated significantly in the presence of the IFN- $\beta$ neutralising antibody with significant interaction between treatment and neutralisation being observed for mRNA expression of Cxcl10 $(p<0.05), M x 1 \quad(p<0.05)$ and Rsad2 $(p<0.05)$ (Fig. 3eg). Expression of OasI was also reduced when IFN- $\beta$ was neutralised but this did not reach statistical significance $(p=0.1072)$ (Fig. 3h).

These data confirm O4-mediated induction of IFN- $\beta$ is responsible for IFNAR1-dependent expression of antiviral ISGs in these CNS cultures, an observation supporting our hypothesis intrathecal synthesis of lipidspecific IgMs can have antiviral properties in the CNS.

\section{Microglia are the major source of Ifnb1 in a cGAS-STING- dependent manner}

To further elucidate the mechanism of action by $\mathrm{O} 4$, we sought to identify those cells responsible for producing IFN- $\beta$. Previous studies indicate microglia are a major source of IFN- $\beta[27,28]$ and may therefore orchestrate ISG expression in other neural cells. We therefore used the colony-stimulating factor 1 receptor (CSF-1R) inhibitor PLX3397 to deplete microglia prior to treating the cultures with O4 or control IgM [29]. PLX3397 reduced Iba- $1^{+}$microglia by $>99 \%$ without affecting viability of the other cell types (Fig. 3i-1). This was accompanied by an almost complete abrogation of Ifnb1 expression in O4-treated cultures (Fig. $3 \mathrm{~m}$ ). We therefore conclude microglia are the major source of O4-induced Ifnb1 expression in myelinating cultures.

To gain understanding as to how O4 upregulates IFN$\beta$ in microglia, we screened a panel of inhibitors that act upstream of known IFN- $\beta$-inducing pathways. Rat myelinated cultures were treated for $6 \mathrm{~h}$ with $\mathrm{O} 4$ combined with vehicle or inhibitor of interest $(10 \mu \mathrm{M})$. Ifnb1 expression was substantially depleted in cultures where cGAS (RU.521) or STING (C-176, $p<0.05)$ were inhibited, and completely ablated by inhibition of TBK1/IKKe (BX795, $p<0.05)$ (Fig. 3n). This would suggest that Ifnb1 after $\mathrm{O} 4$ treatment is upregulated predominantly by a cGAS-STING-TBK1/IKK $\varepsilon$ dependent pathway.

\section{O4 induces cell type specific patterns of ISG expression in the CNS}

Having identified microglia as the major source of IFN- $\beta$, we next asked if IFN- $\beta$ expression orchestrates ISG expression across all major CNS cell types. For many ISGs there are no suitable antibodies commercially available, so we combined Fluorescent In Situ Hybridisation (FISH) with cell-specific antibodies to visualise transcripts encoding candidate ISGs (Cxcl10, $M x 1$, Rsad2 and Oasl) in neurons, oligodendroglia, 


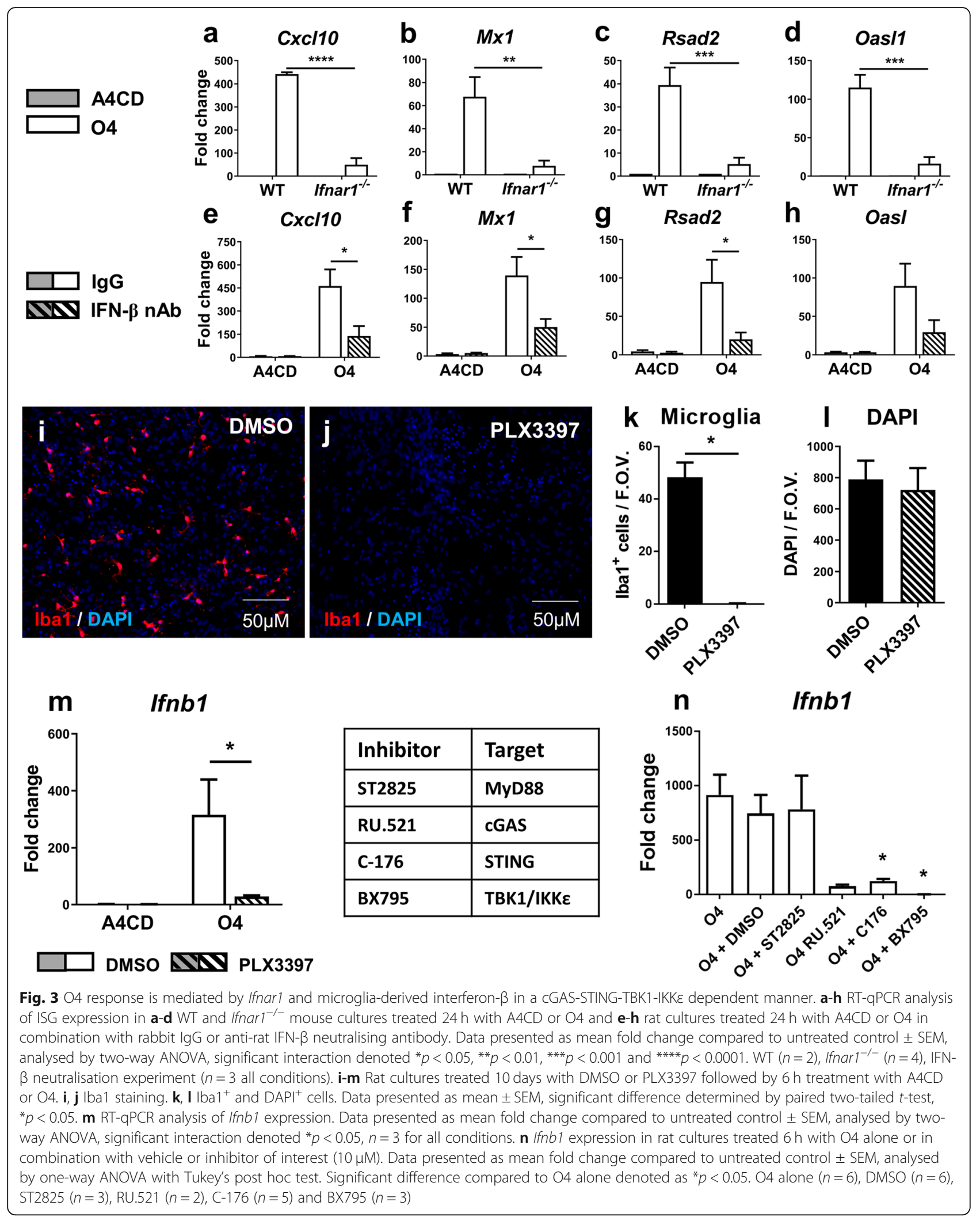




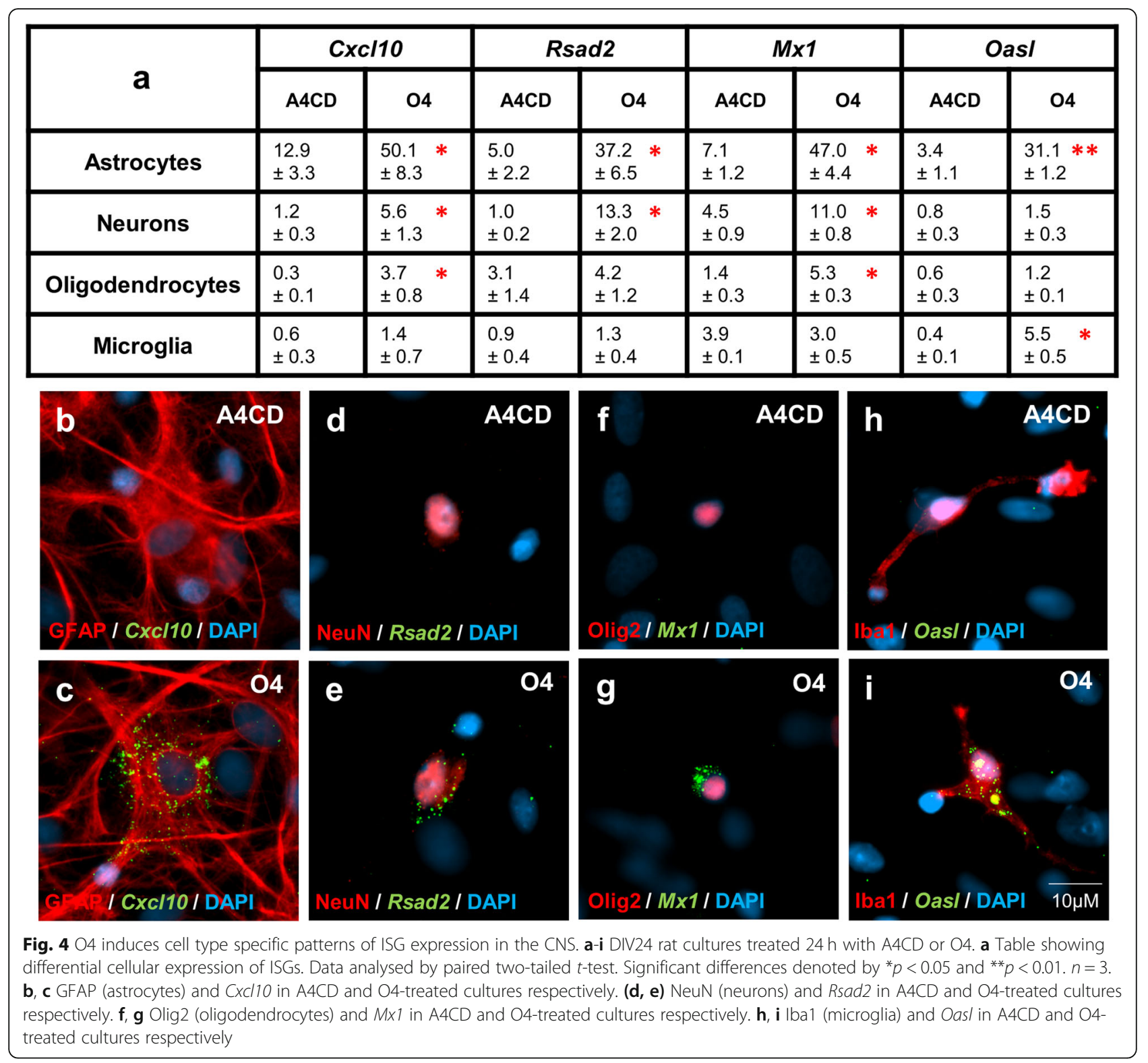

astrocytes and microglia. Compared to A4CD-treated controls, $\mathrm{O} 4$ induced a significant increase in cells expressing these candidate ISGs (Cxcl10 $p<0.001 ; M x 1$ $p<0.001 ; \operatorname{Rsad2} p<0.001$ and Oasl $p<0.01$ ) (Suppl. Fig. 3) and each cell type upregulated at least one ISG (Fig. 4a). Astrocytes upregulated all four ISGs, neurons upregulated Rsad2, Cxcl10 and Mx1, oligodendrocytes upregulated $\mathrm{Cxcl10}$ and $M x 1$ whilst microglia only upregulated Oasl in this model of the CNS (Fig. 4).

These observations reinforce our hypothesis that intrathecal synthesis of lipid-specific IgM protects MS patients from natalizumab-associated PML and presumably other viral infections of the CNS.
Lipid-specific IgM-mediated antiviral responses are not sulfatide dependent

We next asked if the STING-dependent induction of IFN- $\beta$ is dependent on $\mathrm{O} 4$ binding sulfatide; a galactosphingolipid highly enriched in myelin. O4 is polyreactive and not only binds sulfatide but also seminolipid (3-sulfogalactosyl-1-alkyl-2-acyl-sn-glycerol) and a variety of other ligands [30]. To differentiate between these targets we used cerebroside sulfotransferase (CST) deficient mice that lack the ability to synthesise sulfatide and seminolipid [31], resulting in $\mathrm{CST}^{-/-}$cells to which O4 cannot bind (Fig. 5a \& b).

Comparison of cultures from $\mathrm{CST}^{+/+}, \mathrm{CST}^{+/-}$and $\mathrm{CST}^{-1-}$ embryos revealed that specific binding of $\mathrm{O} 4$ to 


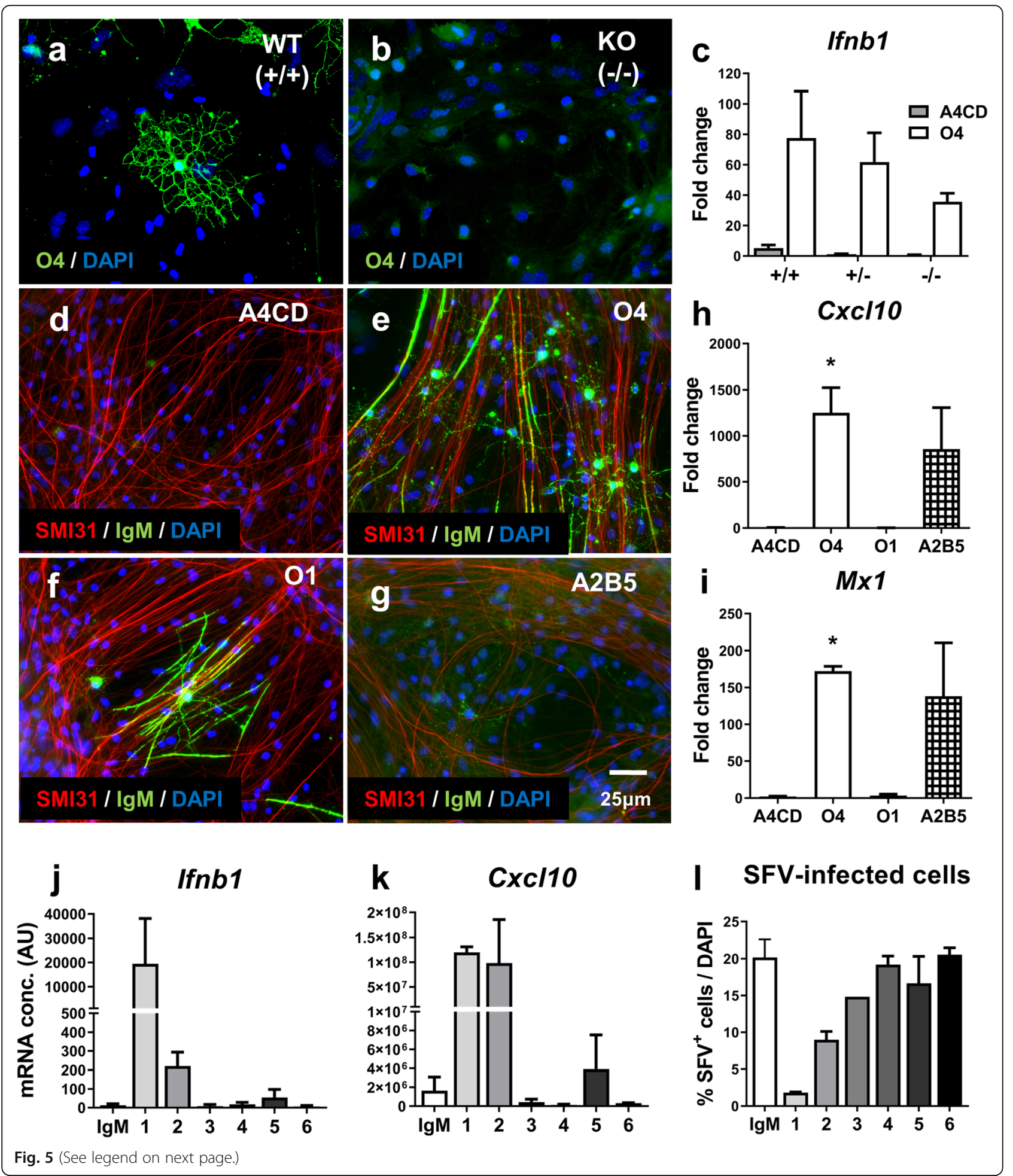


(See figure on previous page.)

Fig. 5 Lipid-specific lgM mediated antiviral responses are not sulfatide-dependent and identification of similar antibodies in human repertoire. a, b 04 staining in WT and $\mathrm{Cst}^{-/-}$mouse cultures respectively. $\mathbf{c}$ Ifnb1 expression in DIV24 $\mathrm{Cst}^{+/+}, \mathrm{Cst}^{+/-}$and $\mathrm{Cst}^{-/-}$cultures treated $6 \mathrm{~h}$ with A4CD or O4. Data presented as mean fold change compared to untreated control \pm SEM and analysed by two-way ANOVA. d-g Representative images of binding patterns of A4CD, O4, O1 and A2B5 in DIV24 rat cultures. $\mathbf{h}$, i ISG expression in DIV24 rat cultures treated 24 h with A4CD, O4, O1 and A2B5. Data presented as mean fold change compared to untreated control \pm SEM and analysed by one-way ANOVA with Tukey's post hoc test. Significant difference compared to A4CD denoted as ${ }^{*} p<0.05, n=3$ for all conditions. $\mathbf{j}-\mathbf{I}$ Screening of patient-derived human IgM antibodies (hlgM's) $\mathbf{j}$ Ifnb1 expression $2 \mathrm{~h}$ post-treatment. $\mathbf{k}$ Cxcl10 expression $24 \mathrm{~h}$ post-treatment. Data represent two technical replicates from one biological $\mathrm{n}$ (DIV24 mouse cultures) and are presented as mean \pm SD. I Immunocytochemical analysis of DIV24 mouse cultures pre-treated $24 \mathrm{~h}$ with hlgM's and infected with SFV. Data presented as mean \pm SD and represent a biological $\mathrm{n}$ of 2 for all conditions except sample $3(n=1)$

sulfatide, seminolipid or any other CST-dependent sulfoglycolipid exposed at the outer surface of myelin and oligodendrocytes was not required for $\mathrm{O} 4$ induction of Ifnb (Fig. 5a-c). Whilst O4-indued Ifnb expression by $\mathrm{CST}^{-/-}$ cultures was lower for $\mathrm{CST}^{+/+}$cultures, this difference did not reach statistical significance and could be due to the lower percentage of microglia in the $\mathrm{CST}^{-/-}$cultures (data not shown). Recognition of cell surface sulfogalactolipids by $\mathrm{O} 4$ is therefore not an absolute requirement to trigger induction of Ifnbl. This was unexpected as our working hypothesis was that induction of antiviral activity involved damage associated molecular patterns (DAMPs) generated in response to $\mathrm{O} 4$ binding to the oligodendrocyte/myelin surface.

This observation prompted us to explore whether other glycosphingolipid-reactive IgM mAbs would also induce Ifnb1 expression in this culture system. This was investigated using $\mathrm{O} 1$ which is specific for galactosyl ceramide [32] and A2B5 which recognises multiple c-series gangliosides [33]. Immunofluorescence staining confirmed $\mathrm{O} 1$ bound extensively to oligodendroglia and myelin (Fig. 5f), whilst A2B5 weakly labelled a population of cells identified tentatively as neural progenitors (Fig. 5g). Strikingly, we found A2B5 upregulated expression of Cxcl10 and Mx1 to levels comparable to that in O4 treated cultures, whereas O1 had no such effect (Fig. $5 \mathrm{~h} \& \mathrm{i})$. These data indicate induction of antiviral activity by lipid-reactive IgM is not restricted to $\mathrm{O} 4$ but can be mediated by other lipid-reactive IgMs and does not require recognition of CNS myelin.

\section{Screening of human-derived IgM antibodies identifies candidate with antiviral properties}

To determine if IgMs with antiviral activity are present in the human antibody repertoire, we investigated a small panel of human IgMs isolated from patients with IgM gammopathies such as Waldenstrom's macroglobulinemia [34]. Using mouse myelinated cultures, we found three out of six tested antibodies induced expression of IfnbI at $2 \mathrm{~h}$ (Fig. 5j) and Cxcl10 at $24 \mathrm{~h}$ (Fig. 5k); shIgM22 (1), 2) rhIgM22 (2) which is a recombinant version of shIgM22 and to a far lesser extent shIgM42 (5). To assess whether induction of Ifnb1 supported a functional antiviral response we pre-treated cultures with human IgMs for $24 \mathrm{~h}$ and then infected them with SFV. We observed a substantial decrease in the percentage of cells infected with SFV in cultures pre-treated with rhIgM22 and to a lesser extent shIgM22 (Fig. 5l); an effect that correlates with their ability to induce Ifnb1. Immunofluorescence staining showed these two antiviral antibodies also bind oligodendrocytes (Suppl. Fig. 4A \& B) whilst the remaining antibodies in this screen target neurons (Suppl. Fig. 4C-E) or failed to bind in culture (Suppl. Fig. 4F).

Together, the data indicate a subset of lipid-specific IgM antibodies exists in mice and humans that can induce a functional antiviral response in the CNS. This previously unreported mechanism offers an explanation for the association between intrathecal lipid-specific IgM and protection against JCV in MS patients.

\section{Discussion}

Sustained intrathecal antibody synthesis is the most consistent and well-documented immunological abnormality associated with MS; its most obvious manifestation being the presence of oligoclonal immunoglobulins in patient cerebrospinal fluid [35]. The specificity profile of this response is complex, but contains a significant component directed against lipid antigens in particular sulfatide (3-O-sulfated galactosyl ceramide) [20, 36, 37]. It has been suggested this lipid-specific antibody response plays an important role in modulating disease activity in the CNS as intrathecal synthesis of lipid-reactive IgM correlates not only with a more aggressive disease course [38], but also a reduced risk of patients developing natalizumab-associated PML [11]. Inspired by the latter report, we hypothesised a subset of lipid-reactive IgMs might enhance innate antiviral activity in the CNS. We now demonstrate that several different lipid-reactive IgM mAbs can initiate a functional antiviral response in primary myelinating cultures that reproduce the cellular and functional complexity of the CNS [21,39]. This response is dependent on cGAS/STING-mediated upregulation of IFN- $\beta$ in microglia, which then triggers IFNA R1-dependent expression of antiviral ISGs in oligodendrocytes, neurons, astrocytes and microglia.

Identification of microglia as the source of IFN- $\beta$ induced by $\mathrm{O} 4$ concurs with studies demonstrating 
microglia are major producers of IFN- $\beta$ in other inflammatory and viral disease models $[27,28,40]$. IFN- $\beta$ subsequently upregulated expression of ISGs in surrounding neurons and glia via activation of IFNAR, which is expressed ubiquitously by cells throughout the CNS [41]. However, the response of individual cells to IFN- $\beta$ will differ due to intrinsic differences in signalling thresholds and basal levels of proteins regulating the downstream response [42, 43]. Indeed, our comparative analyses of four selected ISGs that are upregulated in response to $\mathrm{O} 4$ indicates astrocytes are especially efficient at responding to microglia-derived IFN- $\beta$ (Fig. 4a).

Astrocytes are the major glial cell type of the CNS and together with microglia are integral components of the BBB [44]. For viruses that enter the CNS by crossing the vascular endothelium, astrocytes are the first cells these viruses encounter. The robust astrocytic response to microglia-derived IFN- $\beta$ may therefore represent a critical "gate keeper" function that helps protects the CNS compartment from systemic infections [45, 46]. However, our data demonstrate $\mathrm{O} 4$ not only initiates antiviral activity in astrocytes but also in oligodendrocytes and neurons. This is important as JCV infects all three cell types in PML $[47,48]$, and supports our hypothesis that a subset of lipid-reactive IgMs enhance antiviral activity in the CNS, protecting MS patients from natalizumabassociated PML. We were unable to confirm this directly as JCV is an obligate human pathogen. Nonetheless, our identification of human IgMs with similar antiviral properties, together with reports that IFN- $\beta$ inhibits JCV replication in human glia $[49,50]$ support this concept.

In addition to providing a logical mechanism linking intrathecal synthesis of lipid-reactive IgM with protection from natalizumab-associated PML [11], our data also provide new insight into why this antibody response is also associated with a more aggressive MS disease course [38]. In addition to inducing multiple antiviral genes, $\mathrm{O} 4$ also upregulated expression of a large number of chemokine genes (Fig. 2b, Table S1). Chemokines are important regulators of immune cell migration and play key roles in the development of inflammatory responses in the CNS [51]. We therefore interpret this transcriptional response as a mechanism to recruit immune cells across the $\mathrm{BBB}$ in response to a perceived viral threat. The observed chemokine response is mainly involved in recruitment of $\mathrm{T}$ and $\mathrm{B}$ cells, and monocytes, all of which can mediate tissue damage in neuroinflammatory diseases [52-57]. This multifaceted cellular response is predicted to accelerate clearance of viral pathogens, but in the context of MS may enhance inflammatory activity in the CNS, resulting in a more aggressive disease course.

This is perhaps surprising as IFN- $\beta$ is a wellrecognised treatment for MS. However, we attribute this apparent dichotomy to marked differences in the biological effects of local, endogenous production of IFN- $\beta$ within the CNS as opposed to those induced by systemic treatment in the periphery. Our data indicate induction of IFN- $\beta$ by interferogenic IgM's stimulates a coordinated but sequestered antiviral response in the CNS that includes a pro-inflammatory component predicted to enhance disease activity in MS. In contrast, the mechanisms responsible for the therapeutic efficacy of IFN- $\beta$ in MS remain poorly understood. It is unclear if systemic treatment with IFN- $\beta$ also triggers antiviral activity in the CNS, but its mode of action include effects that reduce leukocyte migration across the blood brain barrier [58-60]. This is the same mechanism by which natalizumab suppresses immune surveillance of the CNS, a major factor contributing to the risk of patients developing PML. As such, this may explain why some of the first cases of natalizumab-associated PML occurred in MS patients undergoing combinatorial treatment with IFN- $\beta[61,62]$.

Whilst PML is relatively rare, many other viruses cause life-threatening infections of the CNS, the prevalence of which is increasing due to the continuing emergence of encephalitogenic viruses [63, 64]. Moreover, in over half of presumptive cases of viral encephalitis the causative agent is never identified [65], and for most viral pathogens there are no effective antivirals available, as a consequence the clinical outcome is often poor [66]. Panviral therapeutic strategies that boost innate antiviral activity in the CNS rather than attempting to target the causative agent specifically may therefore transform treatment of these diseases. Activating skin macrophages at the inoculation site provides pan-viral protection against mosquito-transmitted viruses [67], suggesting a similar outcome might be achieved within the CNS by activating microglia. It would be of interest to determine whether the presence of intrathecal lipid-reactive IgM is correlated to differences in the incidence of complications due to other viruses in the nervous system. Our data obtained using BUNV and SFV as genetically unrelated, model neurotropic viruses support this concept, but there are major challenges associated with using lipid-reactive IgMs to stimulate microglial responses in the CNS.

Challenges of therapeutic use of IgMs include the potential risk of neurological deficits caused by antibodies that can bind to the myelin/oligodendrocyte surface [36, $68]$ and the difficulty achieving sustained high concentrations of IgM in the CNS compartment [69, 70]. Miniaturization of intrathecal pumps may overcome the latter problem, but to develop a safe and more generally accessible pharmacological treatment strategy we must understand how lipid-specific IgMs induce expression of IFN- $\beta$ in the CNS. 
We initially focused on the role of antibody-specificity, as this is the primary factor determining the functional activity of somatically mature antibodies. However, those IgMs inducing an antiviral effect in the CNS are close to germline and polyreactive, features indicating they are natural antibodies [71]. As yet no common reactivity was identified that would account for the ability of O4, $\mathrm{A} 2 \mathrm{~B} 5$ and rhIgM22 to induce IFN- $\beta$ in the CNS. O4 recognizes sulfatide, seminolipid and other targets [30], A2B5 binds multiple c-series gangliosides [72] and rhIgM22 binds one or more unidentified ligands [73]. Notably, O4 and hIgM22 are both natural IgMs with few somatic mutations and we hypothesise their polyreactivity underlies their ability to induce IFN- $\beta$ in myelinated cultures. Our finding that neither sulfogalactolipids (Fig. $5 \mathrm{a}-\mathrm{c}$ ) nor binding to myelin/oligodendrocytes (Fig. 5f-i) are prerequisites to trigger IFN- $\beta$ expression by microglia suggest cellular specificity is not a major factor determining their activity. Based on these observations and our demonstration IFN- $\beta$ induction by $\mathrm{O} 4$ involves activation of a cGAS-STING-TBK1/IKKe dependent pathway, we are currently exploring the hypothesis that interferogenic IgMs enhance delivery of an endogenous cGAS/STING agonist to microglia. A precedent which is provided by studies demonstrating that immune complexes can induce type I IFN expression in plasmacytoid dendritic cells by enhancing delivery of host nucleic acids $[74,75]$.

\section{Conclusion}

In conclusion, we identify a logical mechanism to explain the association between intrathecal synthesis of lipid reactive IgM and decreased incidence of natalizumab-associated PML in MS. This strengthens the case for using the presence of intrathecal lipidspecific IgM for further risk stratification when deciding on treatment regimens for MS patients. Furthermore, we hope this mechanism can be exploited to guide development of pan-viral treatment strategies for viral encephalitis.

\section{Supplementary information}

Supplementary information accompanies this paper at https://doi.org/10. 1186/s40478-020-01011-7.

Additional file 1: Supplementary Figure 1. ISG expression in rat cultures treated 24 hrs with commercial IgM, A4CD and O4

Supplementary Figure 2. Kinetics of O4 induction of type-l interferon signalling. Supplementary Figure 3. Visualisation of ISG expression in rat cultures treated 24 hrs with A4CD or O4. Supplementary Figure 4. Binding patterns of screened human IgMs in DIV24 mouse cultures.

Additional file 2: Table S1. Fifty most upregulated genes upregulated in DIV24 rat myelinating cultures treated 24 hrs with 04 compared to IgM control. Table S2. Significantly altered human disease pathways. Table S3. Significantly altered organismal system pathways. Table S4. Primer sequences.

\section{Acknowledgements}

We thank Hugh Willison and Denggao Yao (University of Glasgow, UK) for providing and genotyping the Cst knockout mice, and Andres Merits (University of Tartu, Estonia) for the Semliki Forest Virus construct. This study was funded by generous grants from Hertie Stiftung and the Naomi Bramson Trust to Christopher Linington; several grants from the MS Society UK to Katja Thümmler, Christopher Linington and Julia M. Edgar; PhD studentships from the Medical Research Scotland (PhD-1031-2016) to Lorna Hayden, Medical Research Council to Katie J. Chapple, and the MS Society UK to Tiia Semenoff; an Medical Research Council New Investigator Research Grant (G1001724) to Clive S. McKimmie, and a Glasgow Children Hospital

Charity Project Support Grant (GCHC/PSG/2018/01) to Christopher Linington and Marieke Pingen.

\section{Authors' contributions}

Conceptualisation: Christopher Linington, Marieke Pingen; Methodology: Lorna Hayden, Julia M. Edgar, Christopher Linington, Xiaohong Shi, Marieke Pingen, Clive S. McKimmie; Investigation: Lorna Hayden, Tiia Semenoff, Verena Shultz, Simon F. Merz, Katie J. Chapple, Katja Thümmler; Resources: Katja Thümmler, Clive S. McKimmie, Xiaohong Shi, Moses Rodriguez, Arthur E. Warrington; Writing original draft: Lorna Hayden, Christopher Linington, Marieke Pingen; Review and editing: Katja Thümmler, Simon F. Merz, Katie J. Chapple, Moses Rodriguez, Arthur E. Warrington, Xiaohong Shi, Julia M Edgar; Visualisation: Lorna Hayden; Supervision: Julia M. Edgar, Christopher Linington, Marieke Pingen; Funding acquisition: Julia M. Edgar, Christopher Linington, Marieke Pingen. The author(s) read and approved the final manuscript.

\section{Competing interests}

rHlgM22 is owned by the Mayo Clinic, Rochester MN USA. Nothing further to declare.

\section{Author details}

${ }^{1}$ Institute of Infection, Immunity and Inflammation, University of Glasgow, Glasgow G12 8TA, UK. ${ }^{2}$ Departments of Neurology and Neurosurgery, Mayo Clinic, Rochester, MN, USA. ${ }^{3}$ Virus Host Interaction Team, Leeds Institute of Medical Research, School of Medicine, Faculty of Medicine and Health, University of Leeds, Leeds LS9 7TF, UK.

Received: 18 June 2020 Accepted: 1 August 2020

Published online: 13 August 2020

\section{References}

1. Tan CS, Koralnik IJ (2010) Progressive multifocal leukoencephalopathy and other disorders caused by JC virus: clinical features and pathogenesis. Lancet Neurol 9(4):425-437

2. Wollebo HS, White MK, Gordon J, Berger JR, Khalili K (2015) Persistence and pathogenesis of the neurotropic polyomavirus JC. Ann Neurol 77(4):560-570

3. Knowles WA (2006) Discovery and epidemiology of the human polyomaviruses BK virus (BKV) and JC virus (JCV). Adv Exp Med Biol 577:19-45

4. Pietropaolo V, Prezioso C, Bagnato F, Antonelli G (2018) John Cunningham virus: an overview on biology and disease of the etiological agent of the progressive multifocal leukoencephalopathy. New Microbiol 41(3):179-186

5. Jelcic I, Faigle W, Sospedra M, Martin R (2015) Immunology of progressive multifocal leukoencephalopathy. J Neuro-Oncol 21(6):614-622

6. Filippi M, Bar-Or A, Piehl F, Preziosa P, Solari A, Vukusic S et al (2018) Multiple sclerosis. Nat Rev Dis Primers 4(1):43

7. Ho PR, Koendgen H, Campbell N, Haddock B, Richman S, Chang I (2017) Risk of natalizumab-associated progressive multifocal leukoencephalopathy in patients with multiple sclerosis: a retrospective analysis of data from four clinical studies. Lancet Neurol 16(11):925-933

8. Gieselbach RJ, Muller-Hansma AH, Wijburg MT, de Bruin-Weller MS, van Oosten BW, Nieuwkamp DJ et al (2017) Progressive multifocal leukoencephalopathy in patients treated with fumaric acid esters: a review of 19 cases. J Neurol 264(6):1155-1164

9. Rudick R, Polman C, Clifford D, Miller D, Steinman L (2013) Natalizumab: bench to bedside and beyond. JAMA Neurol 70(2):172-182

10. Major EO, Yousry TA, Clifford DB (2018) Pathogenesis of progressive multifocal leukoencephalopathy and risks associated with treatments for multiple sclerosis: a decade of lessons learned. Lancet Neurol 17(5):467-480 
11. Villar LM, Costa-Frossard L, Masterman T, Fernandez O, Montalban X, Casanova B et al (2015) Lipid-specific immunoglobulin M bands in cerebrospinal fluid are associated with a reduced risk of developing progressive multifocal leukoencephalopathy during treatment with natalizumab. Ann Neurol 77(3):447-457

12. Ronnblom L, Alm GV, Eloranta ML (2009) Type I interferon and lupus. Curr Opin Rheumatol 21(5):471-477

13. Shi X, van Mierlo JT, French A, Elliott RM (2010) Visualizing the replication cycle of bunyamwera orthobunyavirus expressing fluorescent proteintagged Gc glycoprotein. J Virol 84(17):8460-8469

14. Ulper L, Sarand I, Rausalu K, Merits A (2008) Construction, properties, and potential application of infectious plasmids containing Semliki Forest virus full-length cDNA with an inserted intron. J Virol Methods 148(1-2):265-270

15. Rusinova I, Forster S, Yu S, Kannan A, Masse M, Cumming H et al (2013) Interferome v2.0: an updated database of annotated interferon-regulated genes. Nucleic Acids Res 41 (Database issue):D1040-D1046

16. Rozen S, Skaletsky H (2000) Primer3 on the WWW for general users and for biologist programmers. Methods Mol Biol 132:365-386

17. Carpenter $A E$, Jones $T R$, Lamprecht MR, Clarke $C$, Kang IH, Friman $O$ et al (2006) CellProfiler: image analysis software for identifying and quantifying cell phenotypes. Genome Biol 7(10):R100

18. Schneider CA, Rasband WS, Eliceiri KW (2012) NIH image to ImageJ: 25 years of image analysis. Nat Methods 9(7):671-675

19. Schindelin J, Arganda-Carreras I, Frise E, Kaynig V, Longair M, Pietzsch T et al (2012) Fiji: an open-source platform for biological-image analysis. Nat Methods 9(7):676-682

20. Brennan KM, Galban-Horcajo F, Rinaldi S, O'Leary CP, Goodyear CS, Kalna G et al (2011) Lipid arrays identify myelin-derived lipids and lipid complexes as prominent targets for oligoclonal band antibodies in multiple sclerosis. J Neuroimmunol 238(1-2):87-95

21. Bijland S, Thomson G, Euston M, Michail K, Thummler K, Mucklisch S et al (2019) An in vitro model for studying CNS white matter: functional properties and experimental approaches. F1000Res 8:117

22. Hughes HR, Adkins S, Alkhovskiy S, Beer M, Blair C, Calisher CH et al (2020) ICTV virus taxonomy profile: Peribunyaviridae. J Gen Virol 101(1):1-2

23. Tauro LB, Rivarola ME, Lucca E, Marino B, Mazzini R, Cardoso JF et al (2015) First isolation of Bunyamwera virus (Bunyaviridae family) from horses with neurological disease and an abortion in Argentina. Vet J 206(1):111-114

24. Fragkoudis R, Tamberg N, Siu R, Kiiver K, Kohl A, Merits A et al (2009) Neurons and oligodendrocytes in the mouse brain differ in their ability to replicate Semliki Forest virus. J Neuro-Oncol 15(1):57-70

25. Michlmayr D, McKimmie CS, Pingen M, Haxton B, Mansfield K, Johnson N et al (2014) Defining the chemokine basis for leukocyte recruitment during viral encephalitis. J Virol 88(17):9553-9567

26. Schoggins JW, Rice CM (2011) Interferon-stimulated genes and their antiviral effector functions. Curr Opin Virol 1(6):519-525

27. Roth-Cross JK, Bender SJ, Weiss SR (2008) Murine coronavirus mouse hepatitis virus is recognized by MDA5 and induces type I interferon in brain macrophages/microglia. J Virol 82(20):9829-9838

28. Kocur M, Schneider R, Pulm AK, Bauer J, Kropp S, Gliem M et al (2015) IFNbeta secreted by microglia mediates clearance of myelin debris in CNS autoimmunity. Acta Neuropathol Commun 3:20

29. Elmore MR, Najafi AR, Koike MA, Dagher NN, Spangenberg EE, Rice RA et al (2014) Colony-stimulating factor 1 receptor signaling is necessary for microglia viability, unmasking a microglia progenitor cell in the adult brain. Neuron 82(2):380-397

30. Bansal R, Warrington AE, Gard AL, Ranscht B, Pfeiffer SE (1989) Multiple and novel specificities of monoclonal antibodies $\mathrm{O} 1, \mathrm{O} 4$, and $\mathrm{R}-\mathrm{mAb}$ used in the analysis of oligodendrocyte development. J Neurosci Res 24(4):548-557

31. Honke K, Hirahara Y, Dupree J, Suzuki K, Popko B, Fukushima K et al (2002) Paranodal junction formation and spermatogenesis require sulfoglycolipids. Proc Natl Acad Sci U S A 99(7):4227-4232

32. Sommer I, Schachner M (1981) Monoclonal antibodies (O1 to O4) to oligodendrocyte cell surfaces: an immunocytological study in the central nervous system. Dev Biol 83(2):311-327

33. Saito M, Kitamura H, Sugiyama K (2001) The specificity of monoclonal antibody A2B5 to C-series gangliosides. J Neurochem 78(1):64-74

34. Warrington AE, Asakura K, Bieber AJ, Ciric B, Van Keulen V, Kaveri SV et al (2000) Human monoclonal antibodies reactive to oligodendrocytes promote remyelination in a model of multiple sclerosis. Proc Natl Acad Sci U S A 97(12):6820-6825
35. Stangel M, Fredrikson S, Meinl E, Petzold A, Stuve O, Tumani H (2013) The utility of cerebrospinal fluid analysis in patients with multiple sclerosis. Nat Rev Neurol 9(5):267-276

36. Kanter UL, Narayana S, Ho PP, Catz I, Warren KG, Sobel RA et al (2006) Lipid microarrays identify key mediators of autoimmune brain inflammation. Nat Med 12(1):138-143

37. Ilyas AA, Chen ZW, Cook SD (2003) Antibodies to sulfatide in cerebrospinal fluid of patients with multiple sclerosis. J Neuroimmunol 139(1-2):76-80

38. Villar LM, Sadaba MC, Roldan E, Masjuan J, Gonzalez-Porque P, Villarrubia N et al (2005) Intrathecal synthesis of oligoclonal IgM against myelin lipids predicts an aggressive disease course in MS. J Clin Invest 115(1):187-194

39. Thomson CE, McCulloch M, Sorenson A, Barnett SC, Seed BV, Griffiths IR et al (2008) Myelinated, synapsing cultures of murine spinal cord--validation as an in vitro model of the central nervous system. Eur J Neurosci 28(8):1518-1535

40. Pfefferkorn C, Kallfass C, Lienenklaus S, Spanier J, Kalinke U, Rieder M et al (2016) Abortively infected astrocytes appear to represent the Main source of interferon Beta in the virus-infected brain. J Virol 90(4):2031-2038

41. Zhang Y, Chen K, Sloan SA, Bennett ML, Scholze AR, O'Keeffe S et al (2014) An RNA-sequencing transcriptome and splicing database of glia, neurons, and vascular cells of the cerebral cortex. J Neurosci 34(36):11929-11947

42. Cavanaugh SE, Holmgren AM, Rall GF (2015) Homeostatic interferon expression in neurons is sufficient for early control of viral infection. J Neuroimmunol 279:11-19

43. Kapil P, Butchi NB, Stohlman SA, Bergmann CC (2012) Oligodendroglia are limited in type I interferon induction and responsiveness in vivo. Glia 60(10): 1555-1566

44. Abbott NJ, Patabendige AA, Dolman DE, Yusof SR, Begley DJ (2010) Structure and function of the blood-brain barrier. Neurobiol Dis 37(1):13-25

45. Daniels BP, Jujjavarapu H, Durrant DM, Williams JL, Green RR, White JP et al (2017) Regional astrocyte IFN signaling restricts pathogenesis during neurotropic viral infection. J Clin Invest 127(3):843-856

46. Hwang M, Bergmann CC (2018) Alpha/Beta Interferon (IFN-alpha/beta) Signaling in astrocytes mediates protection against viral encephalomyelitis and regulates IFN-gamma-dependent responses. J Virol 92(10):e01901-17

47. Wuthrich C, Batson S, Anderson MP, White LR, Koralnik IJ (2016) JC virus infects neurons and glial cells in the hippocampus. J Neuropathol Exp Neurol 75(8):712-717

48. Darbinyan A, Kaminski R, White MK, Darbinian-Sarkissian N, Khalili K (2013) Polyomavirus JC infection inhibits differentiation of oligodendrocyte progenitor cells. J Neurosci Res 91(1):116-127

49. O'Hara BA, Atwood WJ (2008) Interferon beta1-a and selective anti-5HT(2a) receptor antagonists inhibit infection of human glial cells by JC virus. Virus Res 132(1-2):97-103

50. Co JK, Verma S, Gurjav U, Sumibcay L, Nerurkar VR (2007) Interferon- alpha and - beta restrict polyomavirus JC replication in primary human fetal glial cells: implications for progressive multifocal leukoencephalopathy therapy. J Infect Dis 196(5):712-718

51. Holman DW, Klein RS, Ransohoff RM (2011) The blood-brain barrier, chemokines and multiple sclerosis. Biochim Biophys Acta 1812(2):220-230

52. McManus C, Berman JW, Brett FM, Staunton H, Farrell M, Brosnan CF (1998) MCP-1, MCP-2 and MCP-3 expression in multiple sclerosis lesions: an immunohistochemical and in situ hybridization study. J Neuroimmunol 86(1):20-29

53. Glass WG, Hickey MJ, Hardison JL, Liu MT, Manning JE, Lane TE (2004) Antibody targeting of the $\mathrm{CC}$ chemokine ligand 5 results in diminished leukocyte infiltration into the central nervous system and reduced neurologic disease in a viral model of multiple sclerosis. J Immunol 172(7):4018-4025

54. Mahad DJ, Ransohoff RM (2003) The role of MCP-1 (CCL2) and CCR2 in multiple sclerosis and experimental autoimmune encephalomyelitis (EAE). Semin Immunol 15(1):23-32

55. Renner NA, Ivey NS, Redmann RK, Lackner AA, MacLean AG (2011) MCP-3/ CCL7 production by astrocytes: implications for SIV neuroinvasion and AIDS encephalitis. J Neuro-Oncol 17(2):146-152

56. Trujillo JA, Fleming EL, Perlman S (2013) Transgenic CCL2 expression in the central nervous system results in a dysregulated immune response and enhanced lethality after coronavirus infection. J Virol 87(5):2376-2389

57. Metcalf TU, Baxter VK, Nilaratanakul V, Griffin DE (2013) Recruitment and retention of $B$ cells in the central nervous system in response to alphavirus encephalomyelitis. J Virol 87(5):2420-2429

58. Kraus J, Voigt K, Schuller AM, Scholz M, Kim KS, Schilling M et al (2008) Interferon-beta stabilizes barrier characteristics of the blood-brain barrier in four different species in vitro. Mult Scler 14(6):843-852 
59. Veldhuis WB, Floris $\mathrm{S}$, van der Meide PH, Vos IM, de Vries HE, Dijkstra CD et al (2003) Interferon-beta prevents cytokine-induced neutrophil infiltration and attenuates blood-brain barrier disruption. J Cereb Blood Flow Metab 23(9):1060-1069

60. Daniels BP, Klein RS (2015) Knocking on closed doors: host Interferons dynamically regulate blood-brain barrier function during viral infections of the central nervous system. PLoS Pathog 11(9):e1005096

61. Langer-Gould A, Atlas SW, Green AJ, Bollen AW, Pelletier D (2005) Progressive multifocal leukoencephalopathy in a patient treated with natalizumab. N Engl J Med 353(4):375-381

62. Kleinschmidt-DeMasters BK, Tyler KL (2005) Progressive multifocal leukoencephalopathy complicating treatment with natalizumab and interferon beta-1a for multiple sclerosis. N Engl J Med 353(4):369-374

63. Kadambari S, Okike I, Ribeiro S, Ramsay ME, Heath PT, Sharland M et al (2014) Seven-fold increase in viral meningo-encephalitis reports in England and Wales during 2004-2013. J Inf Secur 69(4):326-332

64. Munoz LS, Garcia MA, Gordon-Lipkin E, Parra B, Pardo CA (2018) Emerging viral infections and their impact on the global burden of neurological disease. Semin Neurol 38(2):163-175

65. Kennedy PGE, Quan PL, Lipkin WI (2017) Viral Encephalitis of unknown cause: current perspective and recent advances. Viruses 9(6):138

66. Tyler KL (2018) Acute viral encephalitis. N Engl J Med 379(6):557-566

67. Bryden SR, Pingen M, Lefteri DA, Miltenburg J, Delang L, Jacobs $S$ et al (2020) Pan-viral protection against arboviruses by activating skin macrophages at the inoculation site. Sci Transl Med 12(527):eaax2421

68. Rosenbluth J, Schiff R, Liang WL, Dou W (2003) Antibody-mediated CNS demyelination II. Focal spinal cord lesions induced by implantation of an IgM antisulfatide-secreting hybridoma. J Neurocytol 32(3):265-276

69. Neuwelt EA, Minna J, Frenkel E, Barnett PA, McCormick Cl (1986) Osmotic blood-brain barrier opening to IgM monoclonal antibody in the rat. Am J Phys 250(5 Pt 2):R875-R883

70. Eisen A, Greenberg BM, Bowen JD, Arnold DL, Caggiano AO (2017) A double-blind, placebo-controlled, single ascending-dose study of remyelinating antibody rHIgM22 in people with multiple sclerosis. Mult Scler J Exp Transl Clin 3(4):2055217317743097

71. Leslie M (2015) Cleanup crew. Science (New York, NY) 347(6226):1058-1059, 61

72. Kundu SK, Pleatman MA, Redwine WA, Boyd AE, Marcus DM (1983) Binding of monoclonal antibody A2B5 to gangliosides. Biochem Biophys Res Commun 116(3):836-842

73. Wright BR, Warrington AE, Edberg DD, Rodriguez M (2009) Cellular mechanisms of central nervous system repair by natural autoreactive monoclonal antibodies. Arch Neurol 66(12):1456-1459

74. Båve U, Magnusson M, Eloranta ML, Perers A, Alm GV, Rönnblom L (2003) Fc gamma Rlla is expressed on natural IFN-alpha-producing cells (plasmacytoid dendritic cells) and is required for the IFN-alpha production induced by apoptotic cells combined with lupus IgG. J Immunol 171(6):3296-3302

75. Lövgren T, Eloranta ML, Kastner B, Wahren-Herlenius M, Alm GV, Rönnblom $L$ (2006) Induction of interferon-alpha by immune complexes or liposomes containing systemic lupus erythematosus autoantigen- and Sjögren's syndrome autoantigen-associated RNA. Arthritis Rheum 54(6):1917-1927

\section{Publisher's Note}

Springer Nature remains neutral with regard to jurisdictional claims in published maps and institutional affiliations.

Ready to submit your research? Choose BMC and benefit from:
- fast, convenient online submission
- thorough peer review by experienced researchers in your field
- rapid publication on acceptance
- support for research data, including large and complex data types
- gold Open Access which fosters wider collaboration and increased citations
- maximum visibility for your research: over 100M website views per year
At BMC, research is always in progress.
Learn more biomedcentral.com/submissions

